\title{
Book Review Editorial Statement: Mapping the Emerging Field of Media Innovation Research
}

\author{
Arne H. Krumsvik \\ Dept. of Journalism and Media Studies \\ Oslo and Akershus University College of Applied Sciences \\ arne.krumsvik@hioa.no
}

The aim of The Journal of Media Innovations is to serve the professional and research communities involved in the cross-disciplinary field of media innovations, and the Book Review section will be an indispensable part of the Journal from its inception, contributing to mapping this emerging field.

The focus and scope within the reviews section will mirror that of the Journal (exploring how changing technologies and changing modes of usage and engagement with media bring about innovations in media) and will embrace books on method, theory, and other relevant monographs and anthologies. Recognizing that media innovation research will be in continuous dialogues with other disciplines, we will also consider books from further afield.

The success of the Book Review Section of $J M I$ is dependent on the quality and dedication of our reviewers, and I would like to thank Jens Barland (Gjovik University College), Avery Holton (University of Utah), and George Sylvie (University of Texas) for sharing their insight in this inaugural issue.

We seek reviews that provide a critical, balanced, and substantiated assessment of a book's strengths and weaknesses. Reviews should have a target word count of 750-1500 words, and should consider the following:

$\checkmark \quad$ The main ideas and major objectives of the book and how effectively these are accomplished.

$\checkmark \quad$ Its significance in the literature on the subject.

$\checkmark$ The soundness of methods and information sources used.

$\checkmark$ Constructive comments about the strength and weaknesses.

$\checkmark \quad$ An overall assessment of the book.

The Journal of Media Innovations 1.1 (2014): 129-130

(C) Arne H. Krumsvik 2014

http://www.journals.uio.no/index.php/TJMI 
All book reviews should be prepared and submitted following the general Instructions to Authors of this journal. Contributions are fully vetted by the Book Review Editor for organization and content, and finally edited by the JMI Editor. Only substantial changes will be made in consultation with authors.

Books to be considered for review should be sent to Dr. Arne H. Krumsvik, HiOA/IJM, P.O.Box 4 St. Olavs pl., 0130 Oslo, Norway. Potential reviewers are welcome to contact me at arne.krumsvik@hioa.no.

Arne H. Krumsvik, Ph.D.

Book Review Editor 